(C2007 IEEE. Personal use of this material is permitted. However, permission to reprint/republish this material for advertising or promotional purposes or for creating new collective works for resale or redistribution to servers or lists, or to reuse any copyrighted component of this work in other works must be obtained from the IEEE. 


\title{
Ontology for Automated Multi-site Project Management
}

\author{
Hai Dong ${ }^{1}$, Farookh Khadeer Hussain ${ }^{2}$ and Elizabeth Chang $^{3}$ \\ ${ }^{1}$ Hai Dong, DEBII, Curtin University of Technology, Australia, e-mail: hai.dong@postgrad.curtin.edu.au \\ ${ }^{2,3}$ Farookh Khadeer Hussain and Elizabeth Chang, School of Information Systems, Curtin University of Technology, Austra- \\ lia \\ e-mail: (Farookh.Hussain, Elizabeth.Chang) $a$ cbs.curtin.edu.au
}

\begin{abstract}
One characteristic of multi-site project organizations is that people in the organizations are geographically dispersed and from different cultural background, which challenges the senior management to successfully complete the task of project management. Here we introduce the theory of CCCI Metrics in order to solve the issue. By means of ontology technology, we propose an ontology-based system which is to help the senior management to realize the function of automated project management in multi-site project organization.
\end{abstract}

Index Terms-CCCI metrics, project management, ontology

\section{INTRODUCTION}

One characteristic of multi-site project organizations is that people in the organizations are geographically dispersed [3]. With the increase of project outsourcing, project groups and its members are probably located in different areas, from different cultural background and even speaking with different languages [2]. These issues challenge the administration of senior management on projects in project organizations. In addition, until now there is not an existing methodology for tracking project procedures in project organizations.

Against the above issues, this paper is to propose a multi-site project management ontology. From Elizabeth, Dillon and Hussain [1]'s works, we observe that CCCI Metrics is a proper methodology to measure the project processing status. In addition, we introduce a notation system for representing our ontology model. Finally we design the ontology to realize the function of automated project management.

\section{Utilizing CCCI Metrics for Project MaNagement}

CCCI Metrics theory originates from the works of Chang, Dillon and Hussain [1], which is a quantitative methodology to assess trustworthiness of logistic service providers. The essence of CCCI Metrics theory is to measure the trustworthiness value of the providers by means of designing various criterions for the providers and quantitatively evaluating the correlation, the clarity and the importance of each criterion. Here we extend the theory of CCCI Metrics into the field of project management.

CCCI Metrics for project management is utilized to measure the completion status of a project. For a project, many criterions are designed to measure its completion status. In other words, once all criterions are satisfied, the project which the criterions belong to is completed.

CCCI Metrics for project management contain four elements which are:

Correlation of a project (CorrProject) - (1) Degree of Comparison between the actual status of the project completion (ActualCompetionProject) and the mutually agreed status of the project completion (MutuallyAgreedCompletionProject).

$$
\text { CorrProject }=\frac{\text { ActualCompetionProject }}{\text { MutuallyAgreedCompletionProject }}
$$

Correlation of a criterion (CorrCriterion) - A metric qualifies the extent of criterion completion in a project.

Extent: 0 - None/ Partially Completed

1 - Fully Competed - MaxCorrCriterion

Clarity of a criterion (ClearCriterion) - A metric qualifies the extent whether a criterion is mutually agreed between the evaluating person and the evaluated person or not.

Extent: 0 - This criterion is not mutually agreed between two sides.

1 - This criterion is mutually agreed between two sides.

Importance of a criterion (ImpCriterion) - A Metric expresses the importance of a criterion.

Extent: 0 - Not important

1 - Important

2 - Very important

Thus, the equation of project completion status is drawn as (2).

Proiect CompletionStatus $=$ CorrProiect

$$
\begin{aligned}
& =\frac{\text { ActualCompetionProject }}{\text { MutuallyAgreedCompletionProject }} \\
& =\frac{(\text { CorrCriterion } 1 \times \text { ClearCriterion } 1 \times I m p \text { Critertion } 1}{\text { MaxCorrCriterion } 1 \times \text { ClearCriterion } 1 \times \operatorname{ImpCriterion~} 1+\ldots} \\
& \ldots+\text { CorrCriterion } N \times \text { ClearCriterion } N \times \operatorname{ImpCriterionN}) \times 6 \\
& \ldots+\text { MaxCorrCriterion } N \times \text { ClearCriterion } N \times \operatorname{ImpCriterionN}
\end{aligned}
$$

The scope of project completion status includes: 0 - Ignorance 
1 - Completely unfinished

2 - Unfinished

3 - Minimally Finished

4 - Partially Finished

5 - Finished

6 - Completely finished

\section{NOTATION SYSTEM FOR ONTOLOGY REPRESENTATION}

The notation system utilized in the ontology representation is based on Chang, Dillon and Hussain [1]'s work, which consists of three basic notations as Table 1 .

\section{Hierarchy of Project Organization domain Concepts}

In a Project Organization Domain, the Project Organization concept can be seen as a combination of Employee concept and Project concept. Employee also consists of:

- CEO who is responsible for managing all projects in Project Organization.

- Director who is responsible for managing the projects which belong to his/her department in the Project Organization.

- Manager who is responsible for managing the projects which belong to his/her division in each department.

- Personnel who are responsible for the implementation of arranged projects.

On the other hand, according to the theory of CCCI Metrics, Project is divided into different Criterions which are in correspondence with tasks involved in the Project.

The graphical view of Hierarchy of Project Organization Domain Concepts is shown in Fig. 1 through the use of the ontology notation.

Table 1 Ontology notation system

\begin{tabular}{|c|c|}
\hline Ontology Notation & Semantics of the Notation \\
\hline & Double-field Box represents \\
\hline- relation - & $\begin{array}{l}\text { A dotted line represents On- } \\
\text { tology Concept Association Re- } \\
\text { lation which represents a Con- } \\
\text { cept is closely related to another } \\
\text { concept. The relationship name } \\
\text { can be noted above the dotted } \\
\text { line. }\end{array}$ \\
\hline & $\begin{array}{l}\text { Open-arrow line represents } \\
\text { Composition and Aggregation or } \\
\text { Part-of relationship between } \\
\text { Upper Ontology Concept and } \\
\text { Lower Ontology Concept. }\end{array}$ \\
\hline
\end{tabular}

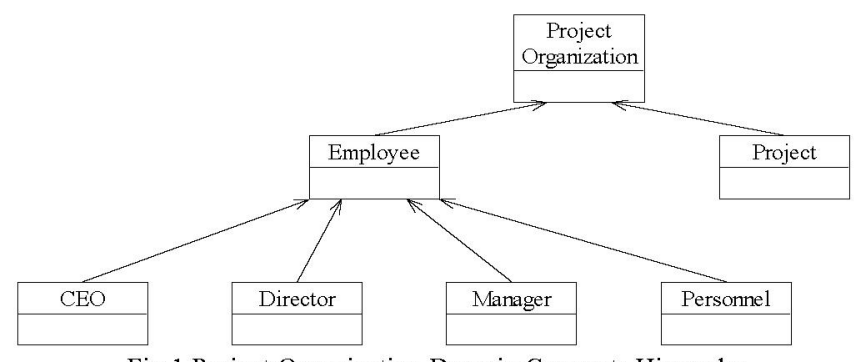

Fig.1 Project Organization Domain Concepts Hierarchy

\section{The Ontology of EMPloyee ANd Its Sub- COMPOSITIONS}

\section{A. Employee Ontology}

In a project organization, the Employee Ontology is defined as the conceptualization of the Employee who has an Employee Position in the organization and is identified by an Employee Name as well as has Responsibilities which include some Projects. (Fig. 2)

We present the Employee Ontology as the combination of the ontology name and a tuple where the elements of the tuple can be complex elements as defined below:

- Employee [Employee Position, Employee Name and Responsibilities] where:

- 'Employee Position' is a unique identification of Employee in a project organization.

- 'Employee Name' is a unique identification of Employee Position in a project organization.

- 'Responsibilities' is an aggregation of Projects which Employees should take part in. Different Employee Positions are in correspondence with different Responsibilities.

\section{B. CEO Ontology and Other Employee's Lower-level On-} tologies

In project organization environments, the CEO Ontology is defined as the conceptualization of the CEO who has a CEO Position in the organization and is identified by a CEO Name as well as has Organizational Responsibilities which include all Projects in the organization. (Fig. 3)

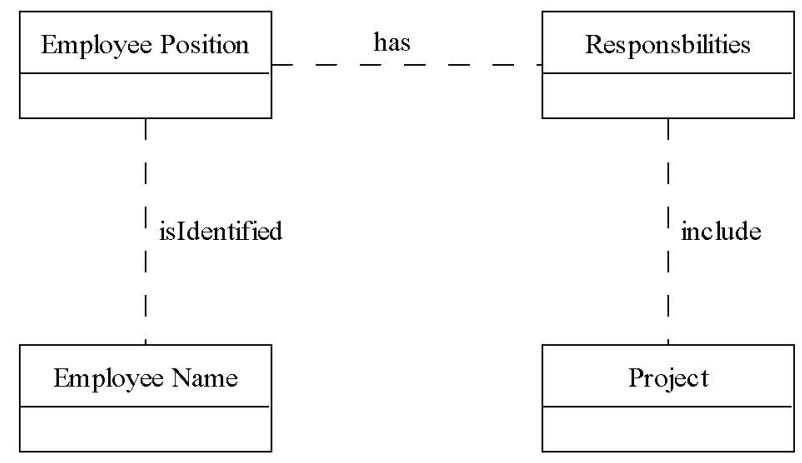

Fig. 2 Employee Ontology 


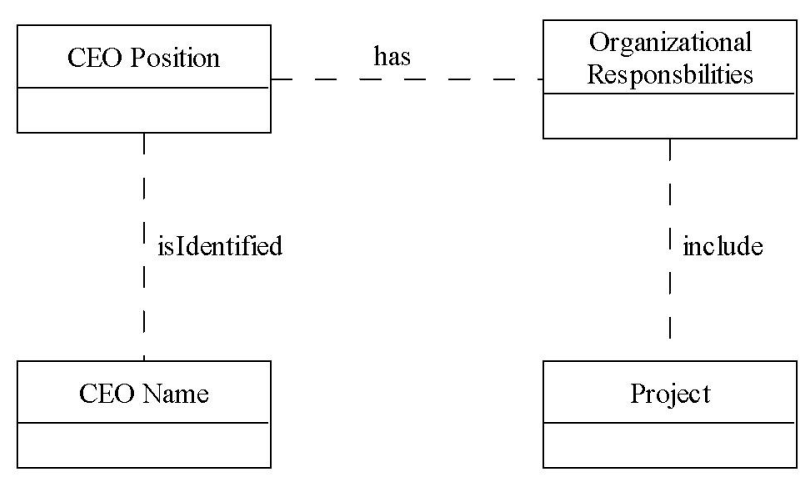

Fig. 3 CEO Ontology

We present the CEO Ontology as the combination of the ontology name and a tuple where the elements of the tuple can be complex elements as defined below:

CEO [CEO Position, CEO Name and Organizational Responsibilities] where:

- 'CEO Position' is a unique identification of CEO in a project organization.

- 'CEO Name' is a unique identification of CEO Position in a project organization.

- 'Organizational Responsibilities' is an aggregation of all Projects involved in a project organization that a CEO manages.

The other three sub-compositions of Employee Ontology - Director Ontology, Manager Ontology and Personnel Ontology inherit all the relations from Employee Ontology and the only difference is the scopes of the inherited concepts' properties.

\section{The Relationships between Employees}

In a project organization, a well-conditioned management structure is beneficial to task distribution and progress evaluation. Here the management structure namely relationships between Employees are described to clarify the management structure in project organizations. (Fig. 4)

In project organizations, the $\mathrm{CEO}$ manages all directors in the project organization. Then each director supervises at least one given manager and every manager manages at least one given personnel. On the other hand, except for CEO who is not managed by anyone, each member in the project organization has been administrated by the only one.

Owing to the differences of management scopes to different level of Employee, the associations are distinct, which are:

- CEO's management scope is limited in all directors in the Project Organization domain.

- Directors' management scope is the given managers in their departments.

- Managers' management scope is the given Personnel in their divisions.

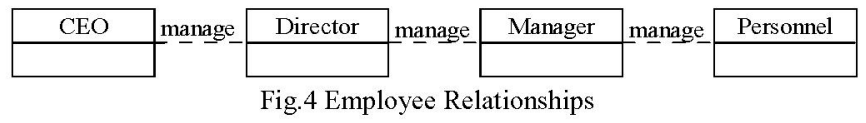

\section{Pro.ject Ontology and Criterion Ontology}

\section{A. Project Ontology}

In a project organization, the Project Ontology is defined as the conceptualization of the concept of Project that is identified by Project Code, is shown Date Started, is responsible to Employee and is evaluated by Project Status. (Fig. 5)

We represent the Project Ontology as the combination of the ontology name and a tuple where the elements of the tuple can be complex elements as defined below:

Project [Project Name, Project Code, Date Started, Responsible People, Project Status and CCCI Metrics] where:

- 'Project Name' usually refers to a Project itself. In project organization environments, a Project Name is seen as a unique identification for Project.

- 'Project Code' is the mixture of numerical symbols and alphabetic symbols, which also can be seen as the unique identification for Project. The use of Project Code mainly focuses on the storage of Projects' records in databases, which is beneficial to the pick-up and the storage of Projects' documentations.

- 'Date Started' refers to the date when a Project begins to implement. In project management, Date Started can be utilized as a means to measure the length of a Project period which can be evaluated as an important quality aspect and a Criterion of Project.
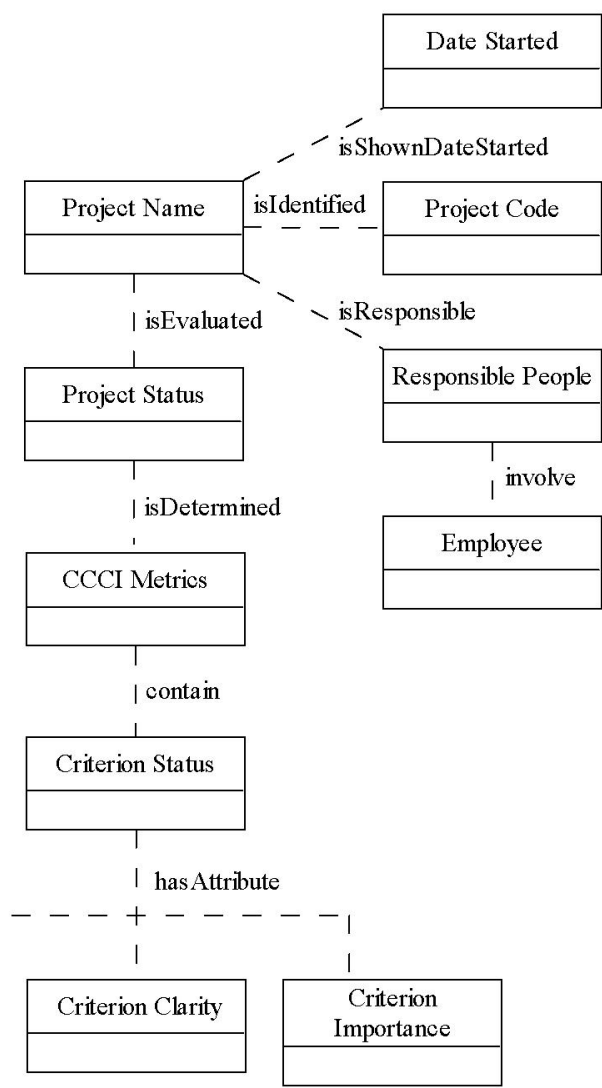

Fig.5 Project Ontology 
- 'Responsible People' is an aggregation of Employees who are relevant to a Project.

- 'Project Status' can be substituted as the concept of Project Status Value. Based on the theory of CCCI Metrics, the scope of Project Status Value is from 0 to 6 , which means the different level of Project Status.

\section{B. Criterion Ontology}

In project organization environments, the Criterion Ontology is defined as the conceptualization of the concept of Criterion that is identified by Criterion No., is shown Date Logged, is responsible to Employee and is determined by Criterion Status which has the attributes of Criterion Completeness, Criterion Clarity and Criterion Importance. (Fig. 6)

We represent the Criterion Ontology as the combination of the ontology name and a tuple where the elements of the tuple can be complex elements as defined below:

Criterion [Criterion Name, Criterion No., Date Logged, Responsible Persons, Criterion Status, Criterion Completeness, Criterion Clarity and Criterion Importance] where:

- 'Criterion Name' usually refers to a Criterion itself. In project organization environments, a Criterion Name is seen as a unique identification for Criterion.

- 'Criterion No.' is the mixture of numerical symbols and alphabetic symbols, which also can be seen as the unique identification for Criterion. The use of Criterion No. mainly focuses on the storage of Criterions' records in databases, which is beneficial to the pick-up and the storage of Criterions' documentations.

- 'Date logged' refers to the date when a criterion has been mutually agreed between an evaluating person and an evaluated person.

- 'Responsible Persons' is an aggregation of Employees who are relevant to a Criterion.

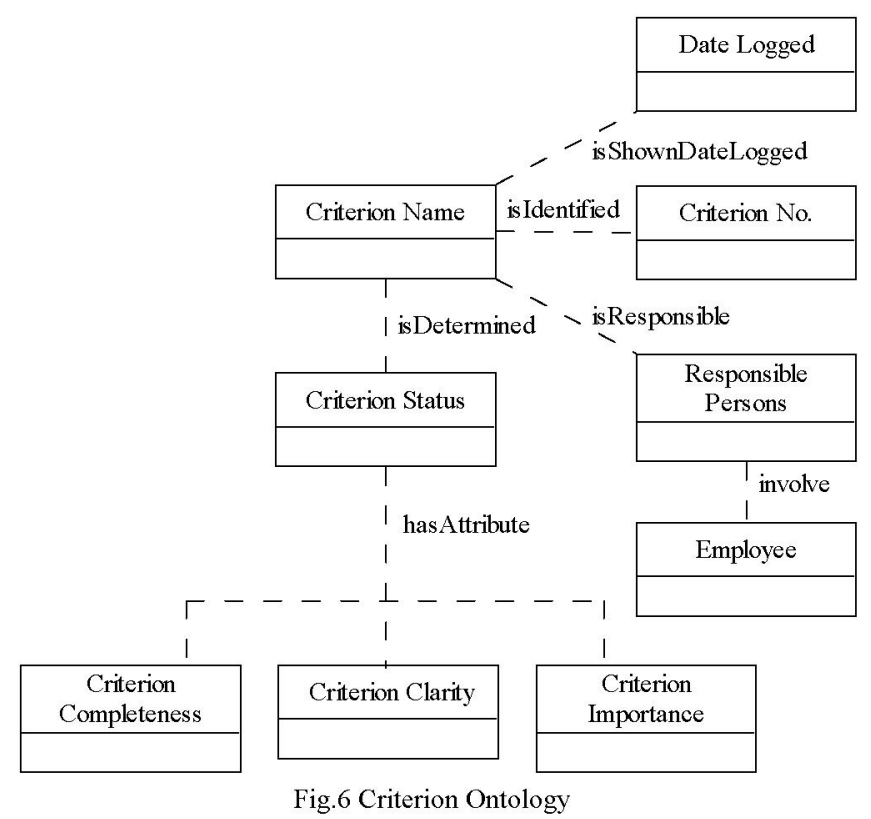

- 'Criterion Status' is a sub-tuple of the Criterion tuple, which uses quantitative means to determine the extent to which a criterion has been completed or delivered up on the mutually agreed Criterion. It consists of three elements Criterion Completeness, Criterion Clarity and Criterion Importance.

- 'Criterion Completeness' is an element of Criterion Status, which qualifies the extent of task completion according to its corresponding Criterion.

- 'Criterion Clarity' is an element of Criterion Status, which qualifies the extent whether a Criteria is mutually agreed between an evaluating person and an evaluated person or not in a Project. Its scope is as below:

- 'Criterion Importance' is an element of Criterion Status, which expresses the importance of a Criterion in a Project.

\section{The Relationship between Project and Criterion}

As explained earlier, a Project can be divided into several Criterions which are in correspondence with tasks or quality aspects of the Project (Fig. 7).

\section{Conclusion And Future Works}

In this paper, against the issues in multi-site project management, we propose an ontology-based methodology to assist senior management to better understand the current status of the projects under their administration, and for the further objective - to promote the automated and simplified project management in project organisations. By means of extending the theory of CCCI Metrics into the field of project management, we attempt to adapt the quantitative methodology to evaluate the completion level of projects. Finally we borrow the ontology notation system from Chang, Dillon and Hussain [1]'s works to create the multi-site project management ontology.

The benefits of this project are concluded as below:

- It realizes the function of managing the multisite project status from the perspective of project management, which is to promote knowledge sharing between senior management and actual executors.

- It can be utilized to distinctly define the tasks of each member in projects, and thus avoiding the confusion of members' understanding to own responsibilities.

- It can be utilized to distinctly define completion criterions for each task, the importance and the clarity of each criterion, which is efficient to assist members fully understand their responsibilities.

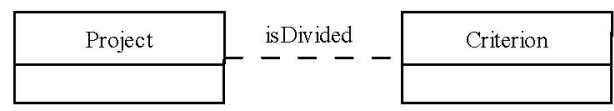

Fig. 7 Relationship between Project and Criterion 
- It adopts quantitative methodology to measure the multi-site project completion status, which is effortlessly understood by organizational management.

The limitations of the project are concluded as below:

- The ontology is not tested in practice, and thus we cannot validate its actual contribution to knowledge sharing activities in project organizations.

- On account of the limitation of the time, we have not designed the API to guide users to use and test this system, which could be proposed in the future.

Therefore, in the future works, we will design the user interfaces by Java Language and implement the ontologybased system in client/server networks or peer-to-peer networks in project organizations and we will survey users' satisfaction status to evaluate the system. In addition, we will attempt to expand our research scope to other project management activities in multi-site project organizations.

\section{REFERENCES}

[1] E.Chang, T.S.Dillon and F.K.Hussain, Trust and Reputation for Service Oriented Environments-Technologies for Building Business Intelligence and Consumer Confidence, John Wiley \& Sons, Brisbane: 2005, pp.131-153.

[2] J.J.J.Kasvi, M.Vartiainen and M.Hailikari, "Managing knowledge and knowledge competences in projects and project organisations," International Journal of Project Management, vol.21, no.8, 2003, pp. 571-582.

[3] I.Ruuska and M.Vartiainen, "Characteristics of knowledge sharing communities in project organizations," International Journal of Project Management, vol.23, no.5, 2005, pp.374-379. 